\title{
MAJOR CURRENT ISSUES CONCERNING CIVIL COMMITMENT CRITERIA
}

\author{
George E. Dix* \\ I \\ INTRODUCTION
}

The present stage of civil commitment law is the product of extensive reform efforts of several sorts. A Draft Act Governing Hospitalization of the Mentally 1 II $^{1}$ was published by the Public Health Service in 1951, but it apparently created little reaction. Reform efforts began in earnest in 1965 when the California Assembly's Subcommittee on Mental Health Services began a creative review of that state's hospitalization process. The subcommittee's report, The Dilemma of Mental Commitment in California, ${ }^{2}$ was published in 1966 and led to the enactment of the Lanterman-Petris-Short Act (LPS Act) ${ }^{3}$ which became effective in 1969. While legislative action has occurred in many other jurisdictions, such action has often been in response to the threat of judicial invalidation of traditional commitment schemes.

Judicial activism began in 1972 when a three-judge federal district court mandated massive changes in the Wisconsin hospitalization process in Lessard $v$. Schmidt. 4 A number of other federal district court cases followed, including both Lynch v. Baxley ${ }^{5}$ and Bell v. Wayne County General Hospital ${ }^{6}$ in 1974. While the number of cases has declined somewhat recently, the 1979 decision in Colyar $v$. Third Judicial District Court ${ }^{7}$ makes clear that even recently revised state commitment statutes can present viable issues for federal litigation. ${ }^{8}$ Interestingly, there is little federal appellate case law addressing commitment criteria. In 1980, however, the Court of Appeals for the Ninth Circuit decided Suzuki v. Yuen, ${ }^{9}$ which constitutes the most definitive federal appellate exposition of federal constitutional limits on commitment standards. State courts have been less prominent in the reform

Copyright $\odot 1983$ by Law and Contemporary Problems

* Vinson \& Elkins Professor of Law, University of Texas.

1. Public Health Service, U.S. Dept. Of Health \& Welfare, Draft act Governing Hospitalization of the Mentally Ill (Pub. No. 51, 1951).

2. Subcommittee on Mental Health Services, California Assembly Interim Committee on Ways and Means, The Dilemma of Mental Commitments in California, A Background DOCUMENT (1966).

3. Cal. Welf. \& INST. Code $\$ \S 5000-5399$ (West 1972 \& Supp. 1982).

4. 349 F. Supp. 1078 (E.D. Wis. 1972), vacated and semanded, 414 U.S 473 (1974).

5. 386 F. Supp. 378 (M.D. Ala. 1974).

6. 384 F. Supp. 1085 (E.D. Mich. 1974).

7. 469 F. Supp. 424 (D. Utah 1979).

8. The Colyar court declared unconstitutional the involuntary commitment statute enacted by the Utah legislature in 1975 .

9. 617 F.2d 173 (9th Cir. 1980). 
movement, although as decisions such as State ex rel. Hawks v. Lazaro ${ }^{10}$ and Commonwealth ex rel. Finken $v$. Roop ${ }^{\prime \prime}$ demonstrate, not entirely inactive. In 1977 the Mental Health Law Project published a model commitment statute which embodied many of the reforms developed or urged in litigation. ${ }^{12}$ Five years later, in 1982, the American Psychiatric Association (APA) approved a set of "guidelines" for legislation providing for the psychiatric hospitalization of adults, ${ }^{13}$ containing association-endorsed proposals for, among other matters, criteria for involuntary treatment.

While much of this reform concerned procedures for invoking involuntary commitment, the criteria for commitment also received considerable attention. The effect was a significant narrowing of the standards. This narrowing has been the result of several concerns which, to some extent at least, are also reflected in federal constitutional doctrines that may affect the validity of state commitment criteria.

One concern-perhaps the most important one-is overbreadth. A commitment criterion that permits the commitment of persons whose detention or treatment is not supported by sufficiently strong interests is overbroad in this sense. As a federal constitutional doctrine, overbreadth is essentially a matter of substantive due process. It requires the judiciary to assess the acceptability of the legislative judgment that the criterion provides for involuntary care of a person whose detention is supported by sufficient governmental interests. Those interests are generally acknowledged to include the government's parens patriae responsibility to care for certain disabled citizens, as well as its police power to protect citizens from harm at the hands of others. In O'Connor $v$. Donaldson, ${ }^{14}$ the Supreme Court, eschewing explicit reliance upon substantive due process, held that retention of an impaired person without treatment and not pursuant to any claim that he was "dangerous" violated his "right to liberty." Presumably even the initial detention of such a person would have the same defect. Justice Stewart, speaking for the Court, provided negative answers to his own rhetorical questions as to whether the right to liberty permitted institutionalization upon a finding of mental illness alone, when the purpose of that institutionalization would be to ensure the person a living standard superior to that which the person would have in the community, or "solely to save [others] from exposure to those whose ways are different. ${ }^{15}$ But the decision provides no hint as to the Court's view of the extent to which

10. 202 S.E.2d 109 (W. Va. 1974).

11. 234 Pa. Super. 155, 339 A.2d 764 (1975), cert. denied, 424 U.S. 960 (1976).

12. Suggested Statute on Civil Commitment, 2 Mental. Disability L. ReP. (ABA) 129 (1977).

13. Sec American Psychiatric Ass'n, Guidelines for Legislation on the Psychiatric HospiTAlization OF ADUlts (1982) [hereinafter cited as GuIDELinEs]. See generally, Board Approves Guidelines for Adult Civil Commitment, Psychiatric News, Dec. 12, 1982, at 1, col. 1, reporting that approval by the Association's Board of Trustees called for some minor additions and changes in the draft approved and cited here. The Guidelines contain the assertion that they constitute "a responsible set of proposals which would improve the process of psychiatric hospitalization in many states." GuIDELINEs, supra, at title page, n.1. But it is further provided that "because local laws, community conditions, and medical practices vary, state and local psychiatric associations and individual psychiatrists may properly support provisions which differ in many respects from these general Guidelines." Id.

14. 422 U.S. 563 (1975).

15. Id. at $575-76$. 
"nondangerous" mentally ill persons can be confined if treatment is provided; of what constitutes "treatment" that will support such confinement; or of what constitutes "dangerousness" for purposes of this analysis.

Apart from overbreadth, commitment standards invoke concern regarding equal treatment or, in constitutional terms, equal protection. ${ }^{16}$ Commitment schemes mean that mentally impaired but not physically ill persons can be subjected to care; moreover, not all mentally ill persons are subject to the process. There is little doubt that rational bases should and must exist for such distinctions as are made between the mentally and physically ill, and between those mentally ill persons who are and those who are not compelled to submit to care.

Finally, frequent concern has been voiced regarding the precision with which the criteria are expressed. The due process prohibition against vagueness is often articulated as the basis of a need for advance notice. ${ }^{17}$ The major function served by a requirement of precision, however, is the reduction of arbitrary application of the criteria by providing those administering them with an objective basis for application. ${ }^{18}$

These concerns have been found controlling in many cases that placed the traditional "need of care and treatment" commitment standards into issue. In Finken, for example, the Pennsylvania criterion requiring that a proposed patient be "in need of care at a [mental health] facility" was found to be overbroad and vague. This result would now seem clearly compelled on "right to liberty" grounds by the dicta in $O^{\prime}$ Connor. But even if such broad and imprecise standards could escape invalidation on their face, there is evidence that as applied they may create an unacceptable risk of arbitrary application.

The question of whether an impaired person requires institutional care requires not only a determination of the person's clinical condition, but also a prediction of community reaction to that condition and the person's response to the community's reaction. The latter two factors are unlikely to be within the realm of a mental health professional's expertise. Commitment practice arguably requires reasonably accurate expert advice which is unavailable in the area of community adjustment. Scheer and Barton examined the community adjustment of three groups of previously hospitalized psychiatric patients. One group of patients had been released by a court against staff advice; another had remained in the hospital until the staff determined that release conditions were optimal; and patients in a third group had made the release decision themselves by escaping. There was no significant difference in adjustment. ${ }^{19}$ If mental health professionals cannot determine better than the patients themselves when continued institutionalization will

16. $C f$. Jackson v. Indiana, 406 U.S. 715 (1972) (subjecting criminal defendant, believed to be incompetent to stand trial, to more lenient commitment standard with less opportunity for release if committed than applies to other impaired persons violates equal protection).

17. See United States v. Powell, 423 U.S. 87, 92-93 (1975).

18. See Giaccio v. Pennsylvania, 382 U.S. 399, $402-03$ (1966).

19. Scheer \& Barton, A Comparison of Patients Discharged Against Medical Advice with a Matched Control Group, 131 AM. J. Psychiatry 1217, 1218 (1974). Later research has been inconsistent. Compare Byers \& Cohen, Predicting Patient Outcome: The Contribution of Prehospital, Inhospital and Post-Hospital Factors, 30 HosP. \& Community Psychlatry 327 (1979) (no significant difference between groups discharged according to or against medical advice) with Withersty, Patient Responsibility and the AMA Discharge: A One-Year Follow-Up 
lead to better community adjustment, it may well be that courts, relying heavily upon professional advice, cannot determine with acceptable accuracy or reliability when institutionalization is "necessary" in the first place.

Few, if any, contemporary commitment criteria rely exclusively upon terms such as those struck down in Finken. The trend is clearly towards requiring that a proposed patient's impairment render the proposed patient dangerous to himself, dangerous to others, or unable to meet personal needs. ${ }^{20}$ While such criteria may lack some of the defects of the more traditional "need of care and treatment" standards, they nevertheless present real problems of overbreadth, equal treatment, and precision. Three concerns evoked by these criteria will be considered here: the formulation and acceptability of a "dangerous to others" standard; the difficulties posed by an "inability to care for personal needs" standard; and the failure of many commitment schemes to require a showing that the proposed patient's decisionmaking ability is impaired.

\section{II}

\section{DANGEROUSNESS TO OTHERS}

The major impact of the reform efforts upon the criteria for civil commitment has been to focus attention upon dangerousness as a consideration in justifying compelled care or treatment. Those dissatisfied with the traditional "need of care and treatment" standard have found a requirement that the proposed patient be found dangerous to others as a result of his impairment to be a conceptually satisfying standard for commitment. The state's interest in the protection of others can support the detention, and reliance upon the more questionable parens patriae responsibility of the state is unnecessary. Nevertheless, a "dangerous to others" standard leaves a number of unanswered questions. ${ }^{21}$

Study, 134 AM. J. Psychiatry 1442 (1977) (those discharged against medical advice had a higher recidivism rate and higher incidence of alcohol and drug abuse).

20. The APA's Guidelines suggest a requirement that "as a result of the severe mental disorder, the person is (1) likely to cause harm to himself or to suffer substantial mental or physical deterioration, or (2) likely to cause harm to others." GuIDELINES, supre note 13 , at $\$ 6(C)(5)$. In addition, the Guidelines suggest that in each case the evidence should be required to show that "the person lacks capacity to make an informed decision concerning treatment." Id. $\S 6(C)(4)$. For further discission, sec infra notes $21,46,53$, and 58. The Guidelines also suggest requirements that the person's disorder be "severe," that commitment be "consistent with the least restrictive alternative," and that the person have refused or be "unable to consent to voluntary admission." Guidelines, supra note 13 , at $\S 6(C)(1)-(3)$. These suggested requirements raise issues beyond the scope of this article.

21. Similar problems are, of course, presented by provisions for commitment because of "danger" to the proposed patient. These are complicated by the frequent inclusion of an alternative provision for commitment upon a showing that a proposed patient poses a less direct and immediate threat to himself because of an inability to provide for personal needs. This is discussed in section III, infra.

The Guidelines define the phrase, "likely to cause harm to others," as used in their proposal as, "likely in the near future to cause physical injury, physical abuse, or substantial property damage to another person." GuIDELINES, supra note $13, \S 3$, at 3 . This, of course, raises many of the issues discussed in this section. It appears intended to encompass more than physical harm but not to permit commitment upon a showing of a risk of "psychological" harm. It is arguable, however, that the term chosen to define the impact upon others beyond physical harm that would suffice-_"physical abuse"-is unclear. No effort is made to limit or define the seriousness of the physical harm or abuse that will suffice; property damage, however, must be "substantial." The harm must be sufficiently likely to occur in the "near future." 


\section{A. Formulation of the Standard}

Various formulations of the "dangerous to others" standard raise several questions concerning the desirable or necessary degree of precision, and the position that should be taken if precision is to be pursued.

First, is it necessary and reasonable to limit the kind of harm which will justify commitment? ${ }^{22}$ If the required harm is physical harm, it can be argued that the criterion will draw an unacceptable distinction between persons who are likely to physically harm others (and are thus subject to commitment) and others who are virtually certain to impose very severe but nonphysical discomfort upon others (but who remain free to do so). A severely impaired family member, for example, can undoubtedly cause substantial family disruption and perhaps long term psychological damage, especially to children. Should a family in such a situation be left with the choice of either rejecting-and ejecting-the impaired member, or of accepting the damage that results from the member's continued presence as a part of the family unit? On the other hand, the difficulty of defining with adequate precision the sort of nonphysical harm that would or should justify commitment may be so great as to justify a physical harm standard. Such a standard might fail to accommodate a few meritorious cases but, nevertheless, would be less subject to arbitrary application than the alternative.

Second, should - or must-any limitation be placed upon the seriousness of the harm to others that will justify commitment? ${ }^{23}$ This may prove quite significant in application. Some proposed patients may be shown to be sufficiently likely to commit at least minor assaults on others, but there may well remain significant doubt as to whether more than minor injury or offense would result. Some criteria and, perhaps, federal constitutional demands require a more serious injury. In Lynch, for example, the court held that federal constitutional requirements demanded a showing of a sufficient risk of "substantial" harm. ${ }^{24}$

Arguably, the state's interest in preventing minor batteries cannot justify the detention of such persons. However, it may be that the task of anticipating not only the likelihood of assaultive and other dangerous conduct, but also the amount of harm that would result, is too difficult a task to expect committing authorities to perform accurately. Under this latter view, a standard adequately limited in other

Finally, the likelihood of that harm occuring is expressed only in terms of a requirement that the harm be shown to be "likely."

22. Some statutes merely refer to "harm" to others. E.g., NEB. REV. STAT. § 83-1009(1) (1976). While others refer to "physical harm," e.g. , ARK. STAT. ANN. \$ 59-1401 (a) (Supp. 1981), several specifically include nonphysical harm, IOWA CODE ANN. § 229.1(2)(b) (West Supp. 1982-83) ("serious emotional injury on members of his or her family or others who lack reasonable opportunity to avoid contact'); HaWAII REV. STAT. \$ 334-1 (1976) ("substantial physical or emotional injury on another").

23. Again, statutes differ. Compare the statutes cited supra note 22 with ILL. ANN. STAT. ch. $911 / 2, \S 1$ 119(1) (Smith-Hurd West Supp. 1981-82) ("serious physical harm") and KY. REV. STAT. \$ 202A.010(5) (1980) ("substantial physical harm"). Broader phrases may be limited by an accompanying requirement of an overt act. While the Pennsylvania statute requires only "danger to others," it also requires proof that the proposed patient attempted to or did cause serious bodily harm to another and that there is a reasonable probability that "such conduct" will be repeated. PA. Stat. ANN. tit. 50, § 7301 (b)(1) (Purdon Supp. 1982-83).

24. Lynch, 386 F. Supp. at 390. 
regards is as narrow and precise as it can realistically be if it includes a requirement of physical harm to justify commitment.

Third, is the period of concern adequately and reasonably defined? ${ }^{25}$ There is general agreement that predictive accuracy decreases as the period of concern lengthens. At some point, it is arguable that the commiting authority will be required to predict dangerous conduct over such a long period that the conclusions will not be sufficiently reliable either to provide support for commitment or to avoid arbitrary application of the criterion. Many of the current, and apparently constitutionally acceptable, formulations of the dangerousness criterion may be of little use in meeting this danger. Lessard, for example, read the Wisconsin statute to require that the harm be "immediate;"26 Bell required an "imminent threat."27 These provisions may convey a general sense of the drafters' intent, but it is arguable that such provisions do not adequately direct-if indeed this is their purpose-the commitment authority not to be concerned with more than several days or weeks of time. The criterion could be phrased in terms of days or weeks. While such a formulation might appear arbitrary, it is no more so than the meaning that might well be given requirements of "imminence" or "immediacy". Further such specificity would avoid the danger that the flexibility in these current requirements will be used to negate their apparent purpose. In Suzuki the Ninth Circuit, without discussion, held that a criterion lacking a requirement that the danger to the proposed patient or others be "imminent" violated the constitutional bar against overbreadth. ${ }^{28}$ No consideration was given to the possibility that this phraseology might not adequately assure that the committing authority's concern was limited to a period during which prediction is acceptably accurate.

Fourth, is the required likelihood of the harm adequately stated? The statutes are generally silent or useless concerning the required risk, ${ }^{29}$ and the case law suggests that constitutional requirements demand little more. Lessard required "an extreme likelihood," 30 while Lynch demanded only that the threat be "real and present." 31 The matter is, of course, capable of specific quantification; there is no drafting reason why a likelihood of $50 \%, 75 \%$, or $87.65 \%$ could not be specified. The objection to such quantification must be that predictive capacities are not

25. The few statutes that address the time frame to be considered usually do so quite generally. Several direct inquiry into the "near future." E.g., ILL. ANN. STAT., ch. 911/2, § 1-119(1) (Smith-Hurd West Supp. 1981-82); Neb. Rev. Stat. § 83-1009(1) (1976); Okla. Stat. AnN. tit. 43A, § 3(0)(1) (West Supp. 1981-82); of. Miss. CODE ANN. (1972) $\$ 41-21-61$ (c) (1972) (at the time of the hearing "or within reasonable time thereafter"). The requirement that the "danger" be immediate, see, e.g. , UTAH CODE ANN. § 647-36(10)(b) (Supp. 1981), WYO. STAT. $\$ 25-3-101$ (ix) (1981), suggests some limitation upon the relevant time frame, but is scarcely specific. But compare the Arizona statute, which directs the committing authority to consider whether the injury to others will occur within 30 days. ARIz. REV. STAT. ANN $\S 36-$ 501(3) (Supp. 1981-82).

26. Lessard, 349 F. Supp. at 1093.

27. Bell, 384 F. Supp. at 1102.

28. Suzuki, 617 F.2d at 178.

29. Some statutes require a "substantial" risk. E.g., ME. Rev. Stat. AnN. tit. 34, § 2251(7) (1978); WASH. REv. CODE ANN. $\$ 71.05 .020(3)$ (likelihood of serious harm "defined as requiring" substantial risk of that harm). But compare the apparently quantitative requirement that the occurence of the required injury be "more likely than not" in N.M. STAT. ANN $\S 43-1-3(M)$ (1978).

30. Lessard, 349 F. Supp, at 1093.

31. Lynch, 386 F. Supp. at 390. 
sufficiently refined to permit implementation in such terms. But this objection misses the mark. A requirement that the committing authority be convinced that a 75\% likelihood exists that the proposed patient would cause physical harm to others over the next " $X$ " days if not detained would not require expert testimony in these exact terms supported by empirical evidence of predictive skills sufficient to make such prediction. It would, however, require the committing authority to face directly whether nonquantitative testimony permits an ultimate conclusion in quantitative terms. This is undoubtedly a difficult issue. It would be better to confront the issue, however, than to avoid it completely as is permitted and perhaps encouraged by even recently enacted commitment criteria.

\section{B. Acceptability of the Standard}

Replacement of the traditional "need of care and treatment" criterion by a "dangerous to others" standard, however formulated, has involved the perhaps uncritical assumption by courts and legislatures that a dangerousness criterion is both more precise and limited than the traditional standard. But recent research on the prediction of assaultive conduct casts doubt upon these assumptions and therefore upon the entire thrust of the reform movement's impact upon commitment criteria.

The few followup studies that have been performed, usually concerning predictions of the long term behavior of convicted criminal defendants, indicate that fewer than half of those persons determined by mental health professionals to be assaultive will actually commit assaultive conduct in the community if not detained. ${ }^{32}$ If these studies are relevant for the administration of commitment criteria, the acceptability of a dangerousness criterion seems questionable. A 50\% error rate raises almost overwhelming overbreadth concerns. The imprecision of evaluation standards that result in such errors raises equally serious concerns regarding arbitrary application. And if so-called dangerous mentally ill persons are in fact likely to engage in assaultive conduct less than $50 \%$ of the time, it is doubtful whether the law is justified in distinguishing them from other mentally ill persons and individuals afflicted with physical impairments.

It is arguable, however, that existing research does not lend itself to application to the matter at issue here. Most of the studies have involved evaluations of presumptively normal persons. If mental health professionals acquire a special facility in predicting conduct because of their training and experience in dealing with mental illnesses, it would seem that this facility would be most developed when applied to persons suffering from such illnesses. ${ }^{33}$ Mental health professionals, and courts aided by such professionals, may be able to predict the assaultive conduct of seriously ill persons more accurately than they can predict the conduct of the subjects in the empirical studies.

In addition, there seems to be widespread agreement that the longer the period covered in prediction, the less accurate the predictions will be. Available empirical

32. See Dix, Clinical Evaluation of the "Dangerousness" of "Normal" Criminal Defendants, 66 VA. L. REv. $523,532-44$ (1980).

33. Id. at 546 . 
evidence generally involves followup periods of several years. If civil commitment dangerousness criteria are construed to require only an inquiry into assaultiveness during the immediate future, it is not unreasonable to expect the evaluations to be significantly more accurate than those studied in the projects reported in the literature. This, of course, suggests that the acceptability, and perhaps constitutionality, of dangerousness standards might depend upon making the time frame express and limited.

One recent study by Steadman and Cocozza examined the behavior of criminal defendants found incompetent to stand trial and evaluated for dangerousness by psychiatrists. ${ }^{34}$ Given the significant impairment required for incompetency, these persons can reasonably be regarded as similar to persons for whom civil commitment might be sought. But on followup, no statistically significant difference in assaultiveness during later release in the community was found. A significant difference was found, however, between the two groups in regard to assaultiveness during prerelease hospitalization. The difference was scarcely impressive; $44 \%$ of those predicted dangerous were assaultive during hospitalization as compared with a $31 \%$ rate of assaultiveness among those labelled nondangerous. ${ }^{35}$ The study confirms that, even with regard to the severely ill, predictions by mental health professionals are better for short term purposes, such as assaultiveness immediately following hospitalization, and become less accurate when they involve persons functioning in the highly variable world outside institutions. Psychiatrists' predictions of short term dangerousness of apparently quite ill subjects, made in the relatively predictable environment of a psychiatric facility, were wrong in over half the cases. The study suggests that mental health professionals may not be able to make predictions concerning proposed patients that are any more reliable than predictions concerning the long term assaultiveness of convicted criminal defendants.

The distressing bottom line is that there is virtually no empirical evidence about the accuracy of professional judgments with regard to the assaultiveness of persons who are mentally ill within the meaning of civil commitment criteria. For example, there is no empirical information on the frequency with which mentally ill persons experiencing psychotic paranoid delusions act assaultively under these delusions. Evidence from other areas, while distinguishable, dictates caution in relying on such predictions of assaultiveness.

\section{Requirement of Overt Conduct}

To the extent that the concerns regarding the prediction of assaultive conduct by impaired persons have merit, perhaps the difficulties can be acceptably met by abandoning reliance upon mere clinical observation and conjecture. A number of courts and legislatures have apparently responded to these concerns by requiring-sometimes as a matter of federal constitutional mandate-that the evi-

34. Steadman \& Cocozza, Psychiatry, Dangerousness and the Repetitively Dangerous Offender, 69 J. CRIM. L. \& CRIMINOLOGY 226 (1978).

35. Id. at $228-29$. 
dence relied upon by the committing authority to find a proposed patient dangerous to others include recent conduct by the proposed patient. ${ }^{36}$

The reasoning underlying the conduct requirements is seldom made clear, which tends to obscure the lack of empirical verification for the assumptions. The reasoning must be as follows: Predictive accuracy, even under a sufficiently limited and precise standard, is so low that the resulting conclusions by the committing authority are so unreliable as to fail to establish an adequate justification for intruding upon the patient's liberty interest under $O^{\prime} C o n n o r$. If, however, the predictive task is undertaken only where the available evidence includes recent conduct on the part of the proposed patient confirming the danger, the resulting conclusions become sufficiently reliable to support commitments. In United States ex rel. Matthew $v$. Nelson ${ }^{37}$ the court noted the absence of empirical evidence concerning the effect upon predictive accuracy of a requirement of overt conduct. However, the court was apparently willing to respect the testimony of expert witnesses that in a "not . . . insignificant" number of cases a credible conclusion as to dangerousness could be drawn from clinical observations alone ${ }^{38}$ because it declined to hold that the absence of a requirement of overt conduct in the Illinois commitment criterion invalidated it on federal constitutional grounds. ${ }^{39}$ Other courts have arrived at the same result, although often without significant explanation. ${ }^{40}$

Rofman, Askinazi, and Fant recently made an effort to test the assumption that overt behavior increases predictive accuracy. The assaultiveness of fifty-nine patients, admitted to the hospital because of their dangerousness to others, during forty-five days of hospitalization was examined. Thirteen of the thirty patients whose certifying physician had noted a specific overt act by the patient, and nine of the twenty-three patients whose record contained no such notice were assaultive; the difference was not statistically significant. ${ }^{41}$ Little reliance can be placed on

36. The statutes vary, but most are quite vague on important aspects of the requirement. Some require that proof include "a recent overt act," e.g., ALA. CODE \$ 22-52-10(a)(3) (Supp. 1981), or a "recent act, attempt, or threat," e.g., HaWAll REV. STAT. § 334-1 (1976). A few are more specific concerning the time frame. The Montana statute requires that the overt act be "sufficiently recent in time as to be material and relevant to [the proposed patient's] present condition." MONT. CODE ANN. § 53-21-126(2) (1981). Pennsylvania demands that the proposed patient be shown to have inflicted or attempted to inflict serious bodily harm on another person within the last 30 days. PA. STAT. ANN. tit. 50, $§ 7301$ (b)(1) (Purdon Supp. 1982-83). Arizona requires, where a threat is relied upon, that the threat have been made within 30 days of the filing of the petition. ARIZ. REV. STAT. ANN. \$ 36-501(3)(a) (Supp. 1981-82). If reliance is placed upon infliction of harm or an attempt to inflict harm, that conduct need only have been within 180 days of the filing of the petition. If, however, the harm inflicted or attempted was "grievous or horrendous," the time frame can be extended "as consideration of the evidence indicates." Id. § 36-501(3)(b).

Generally, the overt act must be part of the proof tending to show the required risk of the specified harm. But a number of statutes appear to make it sufficient that the proposed patient's conduct placed others in reasonable fear of injury. E.g., IDAHO CODE § 66-317(e)(2) (Supp. 1982); WaSH. REv. CODE ANN. \$ 71.05.020(3)(b) (1975 \& Supp. 1981). While this does not appear to change the basic requirement that an actual risk of injury be found to exist, the required conduct is sufficient if it shows a perceived risk of harm by others.

37. 461 F. Supp. 707 (N.D. Ill. 1978).

38. Id. at 711 .

39. Id. at 712 .

40. E.g., People v. Sansone, 18 Ill. App. 3d 315, 309 N.E.2d 733 (1974).

41. Rofman, Askinazi \& Fant, The Prediction of Dangerous Behavior in Emergengy Civil Commitment, 137 
these results, however. Whether assaultiveness during institutionalization is indicative of the accuracy of a prediction concerning assaultiveness if released to the community is doubtful; some persons might well be assaultive in the institutional environment and not in the community. Further, the distinction between the groups-whether the physician noted an overt act-may have been quite fortuitous. Many of those whose physicians did not note such conduct may well have engaged in dangerous behavior. The accuracy of the physicians' conclusions that dangerous conduct occurred in the other cases might be questioned as well. These deficiencies in the study, however, make clear the difficulty of carrying out any well-designed study to investigate the value of recent conduct in improving predictive judgments.

If conduct is to be required, how should that conduct be defined? The prevailing tendency is to require either the actual infliction of harm upon another, the attempt to do so, or the making of a threat to inflict such injury. ${ }^{42}$ But this formulation of the requirement poses a number of questions. Must the harm inflicted, attempted, or threatened be harm of the same magnitude that must be anticipated for commitment? If, for example, the commitment criterion requires a certain risk of serious physical harm, does a requirement that the evidence show an actual infliction of some harm, whether serious or not, adequately assure predictive accuracy concerning serious harm? In regard to attempts and threats, must the trier of fact be convinced that the proposed patient seriously and actually intended to inflict the harm? In regard to attempts, will an attempt suffice if the proposed patient voluntarily gained control and desisted?

Other questions concern the required time frame during which the overt act must have occurred. Some formulations require that the conduct be recent; others do not. What does "recent" mean? The Nebraska Supreme Court held that an act was sufficiently recent if the evidence showed that commitment proceedings were begun and carried out with reasonable diligence following the conduct. ${ }^{43}$ It then proceeded to hold that conduct nine months before the commitment hearing was recent within the meaning of this standard, an apparently indefensible application of the criterion. ${ }^{44}$ The issue should, of course, be resolved with reference to the ultimate goal of improving predictive accuracy. Given the absence of empir-

AM. J. Psychiatry 1061 (1980). For 6 of the 59 patients, data was insufficient regarding assaultiveness prior to hospitalization. Id. at 1062.

42. The APA's Guidelines recommend a requirement that the risk of harm to others (as well as the risk of certain effects upon the person himself) be "evidenced by recent behavior." GUIDELINES, supra note $13, \S 3$, at 3. This raises several of the issues addressed in this subsection. Does "behavior" include verbal behavior such as threats? If so, must the threats be "serious?" When does conduct "evidence" the required risk? And, of course, the lack of precision in the word "recent" may be troublesome. Interestingly, the Guidelines also incorporate a similar requirement into the definition of the impairment required. When the alleged "severe mental disorder" is a condition which "substantially impairs behavior" (as contrasted with a condition which "substantially impairs the person's thought, perception of reality, emotional processes, or judgment"), the definition further adds, "as manifested by recent disturbed behavior." Id. $\S 3$, at 4. Conceivably, then, some cases could present a need for proof of two kinds of conduct, one tending to confirm the existence of the impairment and the other tending to confirm the existence of the required risk of harm.

43. Hill v. County Bd. of Mental Health, 203 Neb. 610, 617, 279 N.W.2d 838, 841 (1979).

44. Id. at 617,279 N.W.2d at 841 . 
ical evidence bearing on how this goal might most effectively be pursued, little more can be done than to invoke unfortunately suspect intuition and common sense. This, however, strongly suggests a requirement that the proposed patient's conduct have occurred within a relatively short time before the decisionmaking point.

Finally, what must be the relationship between the conduct and the ultimate question of fact: whether the proposed patient poses the requisite risk? The general assumption seems to be that the conduct must tend to show the risk, but need not itself be sufficient to establish that risk. Other evidence, such as expert opinion testimony, may also be considered on this. But even if the requirement is so defined, its application may nevertheless cause difficulty. If, for example, a proposed patient suspected of posing a risk of harm to others is shown to have obtained access to a firearm, is this sufficient conduct? Perhaps not, in the absence of further evidence that this conduct was part of a course of planned activity intended by the proposed patient to result in harm of a sort that is sufficient under the remainder of the criterion. This approach, of course, focuses upon the proposed patient's intention and requires that the conduct have been intended by the proposed patient as a step in a course of conduct in turn intended to result in harm. It may be inappropriate to place such reliance upon intention and consciously planned conduct in this context, since many of the persons at issue will undoubtedly suffer from clear impairments. On the other hand, it is by no means clear that the impaired differ from the nonimpaired in any way relevant to this issue. The perceptions and demonstrated willingness of impaired persons to act on those perceptions may be the most reliable indicators of the actual risk these impaired persons present. Moreover, no alternative formulation of the requirement that gives it acceptable precision may be available.

\section{III}

\section{Inability to Care for Personal NeEds}

In an apparent effort to mitigate the effect of a narrow definition of the "danger to self" that will justify commitment, a number of jurisdictions provide the alternative of commitment upon a showing that the subject has been rendered unable to provide for immediate personal needs. The California statute is a frequently followed model. It permits compulsory treatment upon a determination that the proposed patient is "gravely disabled" as a result of a mental disorder. 45 Gravely disabled is defined as "unable to provide for his basic personal needs for food, clothing, or shelter."46

45. Cal. Welf. \& Inst. Code $\S 5350$ (West 1972 \& Supp. 1982).

46. Id. $\S 5008(\mathrm{~h})(1)$ (West Supp. 1982). The APA's Guidelines recommend that commitment be available upon a showing that the proposed patient "is substantially unable to provide for some of his basic needs such as food, clothing, shelter, health or safety." GuIDELINES, supra note $13, \S 3$, at 3 . This is one of the definitions of "likely to cause harm to himself or others or to suffer substantial mental or physical deterioration." Id. $\S 6(\mathrm{C})$, discussed supra note 20 . Unlike the criterion used in the California statute, the Guidelines standard does not in any way limit the "basic needs" which an impaired person must remain able to provide for in order to be free from involuntary hospitalization. This arguably increases the basis for concern regarding the adequacy of the criterion's precision. On the other hand, the Guidelines would 
There seems little basis for quarreling with the proposition that accomodation should be made for impaired persons who are so pervasively impaired as to pose a great risk to their immediate physical well-being even if they are not suicidal. A person in a catatonic stupor, for example, whose complete failure to eat is clearly life threatening might quite properly be compelled to submit to treatment. There is substantial reason, however, to question whether provisions such as those in the California statute are sufficiently precise and limited in scope. What constitutes a "basic need" and what amounts to an inability to provide for that need remains quite flexible. Granting that a complete failure to take any nourishment at all constitutes an inability to provide for one's need for food, does a pattern of living in which one's diet is insufficiently nutritious constitute such an inability as well? In Suzuki, the court concluded that a showing that a proposed patient would cause minor damage to property, even if this were done in such a manner as to amount to a criminal offense, would not provide a constitutionally adequate basis for commitment. ${ }^{47}$ Yet is it not possible that such a proposed patient might be considered gravely disabled on the basis that, because he will be jailed, his conduct will deprive him of the ability to remain at large in the community, and thus of his ability to provide for his own needs?

Perhaps because such provisions for the commitment of a vaguely defined group of gravely disabled persons provide the means to circumvent the troublesome results of narrowing other aspects of the commitment criteria, courts have been unreceptive to challenges to these provisions. In People $v$. Taylor, ${ }^{48}$ for example, the Colorado Supreme Court held that a trial judge erred in requiring the petitioner to show that a gravely disabled proposed patient was also an imminent and substantial danger to herself. ${ }^{49}$ Explaining only that passive inability to care for oneself could be as dangerous or damaging as suicide, ${ }^{50}$ the court failed to address the need to limit the criterion to those situations in which the danger or damage posed was somewhat equivalent to self-destruction. In Doe v. Gallinot, ${ }^{51}$ a federal district court acknowledged that the definition of gravely disabled under the California statute created a "significant risk of erroneous application of the standard . . . ."52 It refused to invalidate the criterion on vagueness grounds, however, and responded to the threat of misapplication by finding a constitutional need for a probable cause hearing to determine whether the patient could be held longer than seventy-two hours.

In view of the widely acknowledged risks posed by these aspects of commitment criteria, is it desirable and perhaps constitutionally necessary that the proof include certain specific past conduct by the proposed patient? It is arguable that impairment of one's ability to meet one's personal needs does not lend itself as well

require proof in all cases of impairment of the proposed patient's decisionmaking capacity; see infra note 53. Perhaps this mitigates any concern that would otherwise be appropriate.

47. Suruki, 617 F.2d at 176.

48. 618 P.2d 1127 (Colo. 1980).

49. Id. at 1134 .

50. Id. at 1137 .

51. 486 F. Supp. 983 (C.D. Cal. 1979).

52. Id. at 991 . 
as the other areas to proof by specific instances of conduct. Perhaps the kinds of situations that might bring an impaired person within this aspect of the criteria are more varied than those that would bring the person within an assaultiveness requirement. But, if true, this arguably increases the need for a showing of conduct that provides sufficient assurance that the proposed patient does, in one of numerous possible ways, meet the statutory criterion.

Care needs to be taken, of course, to formulate the overt act requirement so as to meet the special characteristics of the requirement at issue. It is doubtful, for example, whether a threat or attempt to fail to meet one's personal needs is a meaningful concept. On the other hand, this requirement, unlike the others, might be satisfactorily met by passive inaction as well as affirmative acts. The major question is whether the situation must involve an actual inability to care for personal needs (and, if so, for how long that inability must have existed), or, on the other hand, whether it should be sufficient that the proposed patient was in fact in a situation where the danger of becoming unable to care for personal needs was sufficiently high. In view of the difficulty of developing and applying a standard of the second sort, the first seems preferable and quite likely a constitutional necessity.

\section{IV}

\section{IMPAIRMENT OF DECISIONMAKING CAPACITY}

A few commitment standards require, in addition to other elements, that the committing authority find as a prerequisite to commitment that the proposed patient's impairment has destroyed his ability to make an acceptable or rational choice regarding request for or acceptance of treatment. ${ }^{53}$ Most jurisdictions,

53. There is significant difference among statutory provisions that address impairment of decisionmaking capacity. A number of jurisdictions require a showing of such impairment for any commitment. IOWA CoDE ANN. $\$ 229.1$ (2) (West Supp. 1982-83) (proposed patient must lack "sufficient judgment to make responsible decisions with respect to his or her hospitalization or treatment"); KAN. STAT ANN. §592902(1)(a) (1976 \& Supp. 1981); N.Y. MeNTal Hyg. LAW \$ 9.01 (McKinney's 1978) (proposed patient must be person "whose judgment is so impaired that he is unable to understand the need for such care and treatment”); UTAH CodE ANN. § 64-7-36(10)(c) (Supp. 1981); Wyo. STAT. § 25-3-101 (ix) (1981) (proposed patient must be unable to "comprehend the need for or purposes of treatment and with respect to, whom the potential risk and benefits are such that a reasonable person would consent to treatment"). Other statutes require such a showing where commitment is sought on the basis of the proposed patient's need for care and treatment or "grave disability" (or its equivalent) but not when it is sought on other grounds, such as the danger posed to others or a more immediate danger to the proposed patient. ALASKA STAT. \$ 47.30.070(i) (1979); ConN. Gen. Stat. ANN. § 17-1 76 (Supp. 1982); Del. Code ANN. tit. 16, § 5001(1) (Supp. 1980); Mo. ANN. STAt. § 632.005(9)(b) (Vernon's Supp. 1982); S.C. Code ANN. § 44-17-580(1) (Law. Co-op Supp. 1981). Hawaii requires a showing of "incompetence to determine whether treatment . . . is appropriate" when commitment is sought on the basis of the danger to the proposed patient but not when it is sought on the basis of danger to others. HawaII REV. STAT. $\$ \S 334-1,334-60(\mathrm{~b})(1)$ (1976).

The APA's Guidelines would require in all cases a showing that "the person lacks capacity to make an informed decision concerning treatment." Guidelines, supra note 13 , at $\$ 6(C)(4)$. This is, in turn, defined as meaning:

that the person, by reason of his mental disorder or condition, is unable despite conscientious efforts at explanation, to understand basically the nature and effects of hospitalization or treatment, or is unable to engage in a rational decisionmaking process regarding such hospitalization or treatment as evidenced by inability to weigh the possible risks and benefits.

Id. $\S 3$, at p.2. 
however, have no such requirement. It may well be that such a showing is conceptually and perhaps constitutionally necessary. The issue differs somewhat depending upon whether the commitment is sought under that portion of a commitment standard implementing the parens patriae responsibility for impaired persons, or under other portions resting upon the public interest or police power.

\section{A. Patients' Interest Commitments}

In those situations in which commitment represents an exercise of the state's parens patriae resonsibility for certain of its impaired citizens, it is arguable that the rationale for commitment applies only if a proposed patient is deprived of the ability to maintain responsibility for himself. Further, it may be that there is reasonable assurance that a particular proposed patient lacks such ability only if the committing authority must specifically determine that the proposed patient's ability to make acceptable choices as to whether to submit to treatment is impaired. This is not a recently developed proposal. The Draft Act published by the Public Mental Health Service in 1951 proposed that commitment of one in need of custody, care, or treatment be permitted only if, after having determined that the proposed patient met the initial requirements for commitment, the committing court determined as well that "because of his illness [the proposed patient] lacks sufficient insight or capacity to make responsible decisions with respect to his hospitalization."54

There is authority for the proposition that where commitment is sought pursuant to the parens patriae power, federal constitutional considerations require the approach taken in the Draft Act. In Colyar, the court concluded that under a substantive due process/O'Connor analysis, there is not a sufficient justification for the commitment of a person dangerous to himself or unable to provide for his basic necessities unless, in addition, the petitioner has proven that the person is incapable of making a rational choice concerning submission to treatment. ${ }^{55}$ Further, it held that the criterion must focus upon the process by which the proposed patient decides to reject or accept treatment rather than upon the result of that process, i.e., a decision to reject treatment. The Utah provision in question required a showing that the proposed patient "lacks sufficient insight to make a responsible decision as to the need for care and treatment as demonstrated by evidence of unwillingness or inability to follow through with treatment."56 This, however, was held insufficient to assure an adequate showing that the proposed patient's thought processes (as contrasted with his conclusions) were irrational (as contrasted with responsible). ${ }^{57}$

Conceptually, the arguments for such a requirement seem compelling. Perhaps the major counterargument is the practical danger that, in implementation, the requirement will be relatively meaningless. Judges and juries may be unwilling and perhaps unable to make sophisticated inquiry into whether a pro-

54. Public Health Service, supra note 1 , at $\S 9(\mathrm{~g})$.

55. Colyar, 469 F. Supp. at 431.

56. UTAH CODE ANN. § 64-7-36(6)(C)(i) (1953).

57. Colyar, 469 F. Supp. at 432-33. 
posed patient's disagreement with mental health professionals over the desirability of treatment is the result of a "rational" or legally acceptable process. Some cases will be easy; patients who refuse treatment in response to delusional beliefs that treatment staff members intend to kill them would certainly meet the standard. A patient who has an erroneous view of even temporary life in a public treatment facility or the value of that discomfort in achieving a long range change in condition presents a much more difficult question.

This problem was clearly the basis for the Colyar court's insistence that the statutory criterion focus upon the process by which proposed patients decided to reject treatment rather than the rejection itself, and that it require evidence of an inability to engage in rational decisionmaking processes other than arrival at the "wrong" decision to reject treatment. Given the ease with which a skilled clinician might find pathological characteristics in a proposed patient's thought process, however, the Colyar holding may simply require a somewhat more elaborate semantic defense of a conclusion arrived at because an impaired person disagreed with an expert's opinion that treatment was indicated.

Impaired decisionmaking capacity alone clearly should not permit commitment. It is therefore necessary to consider what anticipated effects of nontreatment, when combined with impaired decisionmaking capacity, should justify compelled care or treatment. There is almost certainly not a sufficient interest in hospitalizing any impaired person merely upon a conclusion that treatment will result in some measurable improvement in his clinical condition. Impaired decisionmaking might, however, be paired with a requirement of "need for care and treatment."58 The addition of the requirement of impaired decisionmaking may overcome the equal treatment and perhaps even the overbreadth objections to the traditional standard, as discussed above.

If concern is focused upon the necessity for commitment as a means of assuring maximum community adjustment, the research suggesting that mental health professionals are no better than patients themselves in making this judgment ${ }^{59}$ poses

58. The APA's Guidelines, while requiring impairment of decisionmaking capacity in all situations, would probably be broadest when commitment is sought on grounds that the impaired person experiences this condition and further "as . . . [a] result of the severe mental disorder . . . is . . . likely . . . to suffer substantial mental or physical deterioration . . . "Guidelines, supra note 13 , at $\S 6(\mathrm{C})(5)$. This provision is developed in the definitional section, which provides that it means that:

as evidenced by recent behavior, the person . . . will if not treated suffer or continue to suffer severe and abnormal mental, emotional or physical distress, and this distress is associated with significant impairment of judgment, reason or behavior causing a substantial deterioration of his previous ability to function on his own.

Id. $\S 3$, at 3 . Thus, commitment on the basis of impaired decisionmaking capacity, in the absence of other considerations sufficient for commitment under the Guidelines, see supra notes 20,21 , 46, would be permitted only upon a showing of a "need" to prevent or alleviate "severe and abnormal" distress, although the nature of that distress is very broadly defined. The rationale for requiring the further showing that the distress be "associated with" deterioration of a previous ability to function independently is not entirely clear. Perhaps, however, it rests on the assumption that a person who never developed a significant ability to function independently exhibits an impairment best addressed through other social responses than civil commitment as mentally ill. The requirement that the deterioration be caused by impairments of the sort described appears to add little to the implied requirement that the deterioration as well as the distress be the result of the severe mental disorder which serves as the basis for regarding the person as impaired.

59. See supra text accompanying note 19. 
significant problems. Strange as it may sound, the research at least raises a real possibility that mental health professionals, and the committing authorities relying on the professionals' advice, are no more able than impaired patients to determine whether institutional care or treatment will improve relatively long term community adjustment. On the other hand, the research may have focused upon patient populations containing few patients as seriously impaired as those who would meet this standard. At least in the absence of evidence directly to the contrary, it may remain reasonable to assume that committing authorities adequately advised by mental health professionals are able to determine with substantially greater accuracy than proposed patients with decisionmaking impairments whether treatment will significantly increase the chances for later community adjustment.

If, however, these objections to a need for care or treatment impaired decisionmaking capacity criterion are found meritorious, it would still be possible to combine the decisionmaking impairment requirement with a mandate that the proposed patient be found unable to care for his immediate physical needs. If this sort of immediate danger to self is required, the objections might be overcome or at least reduced to uncontrolling significance.

\section{B. Public Interest Commitment}

Where the commitment rests not upon the state's parens patriae authority but upon its police power right to act to safeguard the interests of other citizens, the matter becomes more complex. The Draft Act would not require a showing of decisionmaking incapacity where commitment is based upon a showing of likelihood of injury to others or to the patient himself. The rationale for exempting the danger to self situation is not entirely clear; it must, however, rest upon the proposition that significant injury to a person so often has harmful effects upon others that the state has a legitimate police power interest in preventing such injury.

The issue here is, if carefully defined, different from that in parens patriae commitments. Assuming that the commitment criterion requires an adequate showing of some danger in order to invoke the state's legitimate interest in protecting persons other than the proposed patient, the absence of an impairment of the proposed patient's decisionmaking ability may not diminish that interest and certainly does not eliminate it. A state interest sufficient to survive substantive due process scrutiny clearly exists. This does not overcome the problem of unequal treatment, however. Society's interest in protection from unimpaired persons is implemented primarily through the criminal justice system. Conviction of a crime is a prerequisite for imposing protective detention, treatment, or punishment. Crimes are defined in terms of actual demonstrated conduct. In fact, Robinson $v$. Califormia,${ }^{60}$ read in light of Powell $v$. Texas,${ }^{61}$ appears to hold that to define a crime in terms of a defendant's dangerous propensities or "status" would violate the eighth amendment's prohibition against cruel and unusual punishment. If unimpaired citizens cannot be deprived of liberty without proof that they have in

60. 370 U.S. 660 (1962).

61. 392 U.S. 514 (1968). 
fact engaged in society endangering conduct, is it not unfair-and perhaps in violation of equal protection requirements- to subject impaired citizens to detention on the basis of their "status" as dangerous? If so, perhaps a requirement that the impaired citizens be shown to be impaired in such a way as renders them inappropriate subjects of criminal sanction and its threat would justify the difference.

This seems to have been the rationale of the stipulation concerning acceptable commitment standards approved in Wessel $v$. Pryor ${ }^{62}$ In regard to police power commitments, the stipulation required, in addition to a showing of a significant risk of physical harm to others, that the proposed patient "has a substantially diminished criminal responsibility such that [he] appears unable to control his conduct . . . ."63 Thus, state intervention free of the restriction that socially dangerous conduct be proved would be permissible only if, in addition to dangerousness, the petitioner proved that the proposed patient was impaired in such a manner as rendered him unlikely to respond to the threat of punishment which the criminal law imposes upon those who engage in dangerous conduct.

There are several possible arguments that the criteria for police power commitments should not, and certainly need not, include a requirement that impaired decisionmaking capacity be shown. First, mental abnormality may so frequently involve impairment of decisionmaking capacity that a requirement of an express inquiry into the existence of such impairment is unnecessary. There is, however, no evidence that this is true. Moreover, to the extent that there is a factual basis for the argument, it would apply as well to parens patriae commitments. No justification for requiring an express inquiry into decisionmaking impairment only in parens patriae commitments and not in police power commitments is provided by this argument.

Second, the existence of psychological impairment may reasonably substitute for the requirement in the criminal law of a socially dangerous act. Justice Black, concurring in Powell $v$. Texas, urged that the fundamental rationale for elevating the requirement of an act in criminal liability to constitutional status is the difficulty of determining which mere propensities would in fact lead to dangerous conduct and thus social harm. ${ }^{64}$ It may be that our understanding of the nature and course of the impairments afflicting proposed patients is such that our ability to accurately determine when their propensities are real ones is sufficiently developed. Thus, imposing detention even in the absence of conduct does not pose the same danger of error. As was discussed above, however, there is nothing in the empirical literature to establish that the ability to predict the behavior of seriously ill persons is better than the ability to predict what normal citizens will do. The minimal available evidence, in fact, suggests the contrary.

A final response is that to the extent that the commitment criteria require proof of an overt act, commitment criteria may functionally embody the "act" requirement of criminal liability. But there is a significant reason to distinguish between the conduct designated criminal by most criminal statutes and the

62. 461 F. Supp. 1144 (E.D. Ark. 1978)

63. Id. at 1148 .

64. 392 U.S. at 543-44 (Black, J., concurring). 
behavior required by the overt act requirements in commitment criteria. The conduct required for criminal liability is generally conduct that is itself significantly harmful and blameworthy; while considerations of rehabilitation and treatment can legitimately influence sentencing decisions, the outer limit of detention is set by the danger and culpability which the defendant's conduct established. The requirement of an overt act in civil commitment, on the other hand, does not purport to be the major determinant in the decisionmaking process. It appears that those criteria which demand proof of an overt act contemplate that the decision as to whether the proposed patient is sufficiently dangerous will be made on the basis of the testimony of clinicians based on clinical observations and experience as well as on overt behavior. There is no suggestion that the defendant may be found only as "dangerous" as the conduct demonstrates. The function served by the requirement of conduct in commitment criteria, then, is simply not akin to that served by the requirement of an act in the definition of most crimes.

\section{$\mathrm{V}$}

\section{Discussion AND ConClusions}

The trend towards increased reliance upon dangerousness to others in commitment criteria undoubtedly reflects an effort to narrow the standard, although without careful attention to formulation these efforts may be quite artificial. Moreover, the tendency to provide an "inability to care for one's personal needs" standard as an alternative basis for commitment may permit and even encourage circumvention of efforts at restriction. Probably the most interesting conceptual issue presented by current schemes is the desirability and perhaps constitutional necessity of including in some or all of the criteria a requirement that impairment of the proposed patient's decisionmaking capacity be shown. Again, however, concern regarding the manner in which such a requirement would be administered appears quite well-taken.

Unfortunately, the intellectual intricacies and social (and perhaps political) implications of the conceptual issues raised by commitment standards tend to obscure the need for practical concern regarding the enforceability of some alternatives. Empirical evidence concerning the actual effect of various commitment criteria and changes in the criteria, however, is minimal.

Polemics are readily available. Perhaps the most widely publicized is Dr. Darold Treffert's Dying with Their Rights On ${ }^{65}$ presenting case histories of impaired persons killed in the community who, under a broad commitment standard, might have been provided treatment or at least protective care. But comprehensive and well-designed studies on the effect of changes in commitment standards are virtually nonexistent. The extremely ambitious study by the ENKI Research Institute under Albert Urmer on the effect of the implementation of the LPS Act ${ }^{66}$ examined practice before and after that action. But because 1967 legislation had

65. Treffert, Dying With Their Rights On, PRISM, Feb. 1974, at 49.

66. A. Urmer, A Study of California's New Mental Health Law (1969-71) (1972) (published by ENKI Corporation). 
modified the commitment standards so as to make them quite similar to those contained in the LPS Act, ${ }^{67}$ the study could not address the effect of a change in the criteria. It did, however, conclude that despite the requirements that proposed patients constitute a danger to themselves or others, both before and after implementation of the LPS Act, a significant number of physicians appear to have been securing the hospitalization of patients on the basis of the physicians' clinical judgment that treatment was indicated. 68

This suggestion that narrow criteria are likely to be ignored in practice runs throughout the available empirical information. Warren's study of implementation of the LPS Act in one locality ${ }^{69}$ concluded that the statutory standards were not being "strictly applied." 70 In administering the requirement of "grave disability," the court expanded its concern far beyond the effect of nontreatment upon the proposed patients' immediate condition." In regard to the "danger to others" standard, Warren concluded that courts simply ignored the requirement of imminence and seriousness in most cases. ${ }^{72}$ Zander's study of the reaction of Wisconsin state judges to Lessard 73 showed amazing variation. While some judges administered the system with an apparently serious effort to comply with the spirit of the federal court's mandate, ${ }^{74}$ he concluded that the judges in populous Milwaukee County were both inclined and able to circumvent the landmark decision's narrowing of the commitment criteria. ${ }^{75}$

Other studies have produced similar results. Haupt and Ehrlich ${ }^{76}$ report, based on the personal experience of one of the authors, that under the 1976 revisions to the Pennsylvania statute, persons whose commitment is sought because of an impaired capacity to care for themselves are not committed in Philadelphia unless an initial physical examination discloses that they are near death. Munetz, on the other hand, indicates that his apparently more structured study of commitments under the same statute in Pittsburgh led him to the conclusion that $40 \%$ of persons committed there had not committed a dangerous act and "most" of these were not perceived to be so impaired that "without treatment they would have come to severe bodily harm or death within thirty days," as the statute purports to require. ${ }^{77}$

Lelos $^{78}$ studied the commitments of seventy-six patients under the reformed Massachusetts criteria. He concluded that in thirty-two of the seventy-six cases-

67. 1967 Cal. Stat. ch. $1652, \S 1$ (repealed 1969). Sec also 1968 Cal. Stat. ch. $798, \S 1$ (repealed 1969).

68. A. Urmer, supra note 66 , at 116 .

69. Warren, Involuntary Commitment for Mental Disorder: The Application of Califomia's Lanterman-PetrisShort Act, 11 L. \& SoC. REv. 629 (1977).

70. Id. at 647 .

71. Id. at 633 .

72. Id. at 642 .

73. Zander, Civil Commitment in Wisconsin: The Impact of Lessard v. Schmidt, 1976 WIS. L. REV. 503.

74. Id. at $539-42$ (implementation in Dane County).

75. Id. at 547-48 (implementation in Milwaukee County).

76. Haupt \& Ehrlich, The Impact of a New State Commitment Law on Psychiatric Patient Careers, 31 HosP. \& Community Psychiatry 745 (1980).

77. Munetz, Feedback, 32 Hosp. \& Community Psychiatry 284 (1981).

78. National Institute of Mental Health, Givil Commrtment and Social Policy 102 (1978) 
or $42 \%$-commitment was ordered despite the absence of adequate evidence. Hiday's study of implementation of the 1973 revision of North Carolina's commitment statute ${ }^{79}$ is clouded by her definition of imminent danger as requiring a dangerous act within a week prior to the filing of the petition. The statute contained no such requirement, so her conclusions may overstate the number of commitments unsupported by the statutory requirements. She concluded that twentyseven of the forty-three commitments followed hearings in which the proposed patient was not shown to have met the standard. ${ }^{80}$ Perhaps most distresssing, in ten cases- $16 \%$ of the contested hearings observed-the judge made an express statement from the bench acknowledging that the order of commitment was being entered despite the absence of evidence supporting the psychiatrists' conclusory opinion that the proposed patient was dangerous. ${ }^{81}$

lowa Law Review students examined forty-seven commitments under the recently revised Iowa commitment statutes, ${ }^{82}$ which required a showing of dangerousness based on evidence including a recent overt act by the proposed patient, and a demonstration that the proposed patient lacked the judgmental capacity to determine his need for treatment. Although thirty-one of the files included the referees' findings of fact, judgmental capacity was mentioned in only five cases. This led the students to conclude that "judgmental incapacity is very rarely systematically evaluated."83 Examination of the records of the forty-four patients detained for a significant period showed that eighteen records (41\%) contained no indication of a recent overt act or threat. ${ }^{84}$

Some indirect efforts to examine the impact of the 1976 changes in the Pennsylvania statute demonstrate the methodological problems of directly addressing the question of the impact of a change in standards. Two recent studies attempted to develop evidence bearing on whether or not the new restrictive standards were causing some "nondangerous" mentally ill persons to be incarcerated, but through the criminal justice system rather than the civil commitment system. Bonovitz and Guy examined the psychiatric services in the jail servicing the Philadelphia area. ${ }^{85}$ They found that after implementation of the restrictive criteria, requests from jail staff for psychiatric consultations regarding jail inmates rose substantially. ${ }^{86}$ They also found that jail inmates admitted after the reform were less likely than those admitted before the reform to have committed a violent crime and more likely to have been arrested fewer times than those admitted before the

79. Hiday, Reformed Commitment Procedures: An Empirical Study in the Courtroom, 11 L. \& Soc. REV. 651 (1977).

80. Id. at 662-63. In another study of 454 hearings, however, the same author found that only 16 (or $6.8 \%$ ) of the cases resulted in commitment on less than adequate evidence of imminent danger. Hiday, Courl Decisions in Civil Commitment, Independence or Deference?, 4 INT'L. J.L. \& PsYCHIATRY 159, 166 (1981).

81. Hiday, supra note 79 , at 664 .

82. Contemporary Studies Project, Involuntary Hospitalization of the Mentally Ill in Iowa: The Failure of the 1975 Legislation, 64 IoWA L. REV. 1284 (1979).

83. Id. at 1381 .

84. Id. at 1383 .

85. Bonovitz \& Guy, Impact of Restrictive Civil Commitment Procedures on a Prison Psychiatric Service, 136 AM. J. Psychiatry 1045 (1979).

86. Id. at 1046. 
reform. Post-reform inmates were more likely to have committed minor offenses, such as disorderly conduct or trespass, and to have been initially arrested at the request of their families. ${ }^{87}$

This support for the hypothesis that nondangerous mentally ill persons were being treated as criminals was contradicted in a study by Bonovitz and Bonovitz which examined police practices in one Pennsylvania area. ${ }^{88}$ Statistics showed that mental-illness-related incidents handled by police increased dramatically and more than other incidents after the implementation of the revised statute; but record-keeping problems clouded this conclusion and the reasons for any such actual increase as existed were unclear. $^{89}$ An examination of 100 incidents in which police came upon an apparently mentally ill person violating the law suggested a reluctance to process these persons as criminals. Ten cases involved assaults. Only in the one case involving an apparent felony was an arrest made; the others resulted in referral of the subject to a mental health facility. The remaining ninety incidents (in which the absence of assaultive conduct suggested that commitment was not an available alternative) resulted in only twelve arrests. $^{90}$

Haupt and Ehrlich studied samples of patients admitted to the hospital before and after the reform of the Pennsylvania statute. ${ }^{91}$ They found no difference in the number of admissions, the proportion of involuntary admissions, and the length of stay. ${ }^{92}$ They did, however, note that after the implementation of the reform, the percent of patients discharged against medical advice (AMA) rose from $9 \%$ to $27 \%$. AMA patients had shorter lengths of stay than other patients, and were more often rehospitalized and provided emergency treatment. A higher proportion of AMA patients discharged after the reform implementation failed to reach outpatient programs to which they had been referred. Implementation of a narrow dangerousness standard, the authors concluded, can result in shorter lengths of stay and in this fashion can contribute to a situation in which insufficiently improved patients are discharged only to return for further needed care. ${ }^{93}$

Hiday and Markell used the data compiled in Hiday's study of North Carolina commitments in an effort to determine the effect of a more restrictive assaultive standard. ${ }^{94}$ They considered 113 cases in which evidence was offered in an effort to establish that the proposed patient would engage in assaultive behavior. If evidence of an actual assault or a threat to assault accompanied by some effort at implementation were required, they concluded, only $33 \%$ of the cases would result in commitment; if the conduct were required to have been within one week of the filing of the petition (or after the filing but before the hearing), only $23.9 \%$ would

87. Id. at $1047-48$.

88. Bonovitz \& Bonovitz, Diversion of the Mentally Ill into the Criminal Justice System: The Police Intervention Perspective, 138 AM. J. Psychiatry 973 (1981).

89. Id. at 974.

90. Id. at 975-76.

91. Haupt \& Ehrlich, supra note 76.

92. Id. at 747.

93. Id at 748-50.

94. Hiday \& Markell, Components of Dangerousness-Legal Standards in Civil Commitment, 3 INT'L J.L. \& Psychiatry 405 (1980). 
justify commitment. ${ }^{95}$ But their methodology suggests caution in relying upon the results. It may well be that in many of the cases they judged insufficient to meet the standard, evidence of conduct - perhaps even recent conduct-was available and would have been presented had the petitioner known that the applicable standard required evidence of this sort.

In contrast to these studies of the tightening of commitment criteria, Miller and Piddleman ${ }^{96}$ examined samples of hearings before and after a 1979 change in North Carolina's commitment law that significantly loosened the standards. Although they found that the courts committed a higher percentage of persons recommended for commitment after the change in the criterion, they concluded that this was caused by changes in the roles and philosophies of the lawyers involved rather than by the liberalization of the formal law.97 "Fine distinctions in statutory definitions, like the precise meanings of words such as 'dangerousness,' 'mental illness,' and 'grave disability," " they suggested, "have little effect on the outcome of hearings." 98

As this review indicates, reliable empirical evidence as to the effects of narrow commitment criteria of various sorts is minimal. There is simply no basis for judging how many persons with what sort of impairments who are committed under broad traditional standards do or would go without treatment under the new narrow criteria. Many who might not come within the new standards may, of course, be persuaded to receive treatment on a voluntary basis. The significance of this, however, depends heavily upon the extent to which, if at all, this persuasion involves techniques that render the situation indistinguishable from overtly compelled treatment. To what extent, if any, are persons who would otherwise be in treatment programs channeled into the criminal justice system, and with what results? Involvement in the criminal justice system, of course, may lead to treatment and perhaps to a shorter period of detention than would civil commitment. To the extent that persons are not treated as a result of narrow criteria, what is the impact? Are their lives shortened or rendered significantly less fulfilling as a consequence?

The available evidence, despite its inadequacies, does strongly suggest that full

95. Id. at 412-13. Lipsitt and Lelos studied 76 commitment hearings held in Massachusetts after enactment of a statutory requirement of "overt conduct." In 23 of the 53 cases resulting in commitment, they reported no such evidence. Lipsitt \& Lelos, Decision Makers in Law and Psychiatry and the Involuntary Civil Commitment Process, 17 Comm. Mental Health J. 114, 120 (1981). But another report of the same study indicates that 19 of these 23 cases came from one court hearing the many cases generated by a nearby facility for so-called violent patients. Lelos, Courtroom Observation Study of Civil Commitment, in A. MCGARRY, R. Schwitzgebel, R. LipsitT \& D. Lelos, Civil Commitment and Soclal Policy 166-67 (final report of The Laboratory of Community Psychiatry, Harvard Medical School, 1978).

96. Miller \& Piddleman, Involuntary Civil Commitment in North Carolina: The Result of the 1979 Statutory Changes, 60 N.C. L. REV. 985 (1982).

97. Id. at 1002 . This explanation was also useful in explaining the further observation that the commitment courts released a smaller percentage of persons whose commitment was opposed by medical personnel after the change. Id. at 1025. Among the effects of the change in the lawyers' roles was the increased input from community sources. The communities' demands for institutionalization of deviants may exceed the substance of criteria promulgated by legislatures or the standards applied in practice by mental health professionals.

98. Id. at 1024 n. 147 . 
enforcement of narrow standards is unlikely, at least on a uniform basis. It is important to explore the reasons for this. The demonstrated tendency to continue "business as usual" may be partially explained by inertia and reluctance to undertake "new" tasks. Insofar as this explains the nonenforcement that has been or will be demonstrated, it suggests that "test cases" or legislative reform only begin the task and that skillful grass roots efforts to persuade those "on the line" to carry out the mandate is essential to effective reform.

It may also be true, however, that nonenforcement reflects a pervasive community demand that impaired persons who fail to meet the narrow standards be "dealt with" in some manner not readily available at present. To the degree that this can be demonstrated, the problem becomes more difficult. If the narrow criteria are based upon a completely unrealistic view of what is acceptable to the community, implementation may be impossible. The promulgation of standards impossible of accurate application may be the worst of all possible worlds. By divorcing itself entirely from what can reasonably be expected, the law may lose whatever ability it would otherwise have to achieve less comprehensive goals. If the legal standard is inherently impractical, those administering the system may cease entirely to look to the formal law for practical guidance in day-to-day activities. This, of course, encourages development of an essentially lawless system of actual justice. It is by no means clear that, given the constitutional and policy considerations, those commitment criteria that are most conceptually satisfying are inherently impractical. But the empirical evidence sufficiently suggests this possibility to make further inquiry a matter of high priority. ${ }^{99}$

99. Recent legislative action removing some restrictive aspects of commitment criteria has been noted and has led to the suggestion that there may be a trend towards broader standards. See Hiday, supra note 80 , at 159 n.1. 
